\title{
The Optimization of Hybrid Air Ventilation System Combined with Silica Gel and Thermoelectric Using Monitoring Control
}

\author{
Jirod Chaisan, Somchai Maneewan, Chantana Punlek \\ Research and Energy Management Unit, Faculty of Science, Naresuan University, Phitsanulok, Thailand
}

\begin{tabular}{l}
\hline \hline Article Info \\
\hline Article history: \\
Received Feb 14, 2018 \\
Revised Aug 23, 2018 \\
Accepted Sep 12, 2018 \\
\hline
\end{tabular}

\section{Keyword:}

Cabon dioxide

Dehumidification

Indoor air quality

Monitoring control

Thermoelectric

\begin{abstract}
In this paper, the experimental is evaluated temperature, humidity and air pollution from $\mathrm{CO}_{2}$ by monitoring control of hybrid air ventilation for producing fresh air. The experimental divided into 2 conditions: hybrid air ventilation on-off, recovery silica gel unit. That research consider of a voltage of thermoelectric devices relative with air cooling under thermal comfort zone Thailand climate conditions. In the experimental was designed by the DOAS system (dedicate outdoor air system) concept. Whereas, the hybrid air ventilation was improved by old air ventilation which the hybrid air ventilation combined with silica gel unit and thermoelectric device. Monitoring control is written by Arduino program that is open source for control performance of processes such as sensors, electric current and fan unit. That working is specified temperature and humidity Thailand thermal comfort range. In the part of $\mathrm{CO}_{2}$ was released rate approximately $900 \mathrm{ppm}$ corresponded with indoor air quality standard (IAQs). The results of experimental suggested that in case of hybrid air ventilation system explained thermal, humidity and $\mathrm{CO}_{2}$ distribution due to the system was adapted significantly in the comfort zone temperature and humidity about $28^{\circ} \mathrm{C}$ and $58 \%$ respectively. However, the $\mathrm{CO}_{2}$ released into the hybrid air ventilation although control during $900-1,000$ ppm. High $\mathrm{CO}_{2}$ concentration in comfort zone used the hybrid air ventilation that decreased $\mathrm{CO}_{2}$ inlet under ASHRAE 62.2. Therefore, the experimental is an evaluation of monitoring control hybrid air ventilation for management comfort zone. Finally this research concept of the optimization of the hybrid air ventilation combination with thermoelectric devices and silica gel unit.
\end{abstract}

Copyright (C) 2018 Institute of Advanced Engineering and Science. All rights reserved.

Corresponding Author:

Somchai Maneewan,

Research and Energy Management Unit,

Faculty of Science, Naresuan University,

Phitsanulok, 65000, Thailand.

Email: somchaim@nu.ac.th

\section{INTRODUCTION}

In the present, the new investigation and research topics have studied by the engineering, scientist, etc. that realize to the environment. Including of the world is affected by global warming and climate change. The high outdoor air temperature impact to the occupants inside. Due to a lot of a people spent their times more than 6-8 hours in the building such as working, relaxing, sleeping and other activity [1]. Therefore, the thermal comfort and indoor air quality (IAQs) are essential to designation for the building. However, the losing thermal comfort zone consists of heating, lighting, air pollution, bacteria, humidity and a lot of people per room [2]. Thus, the solution is using ventilation and air condition system inside the building. But the air condition system demands high energy consumption that influences to energy costs.

So, the research topic has an assumption for the improvement of older air ventilation system. Due to older air ventilation system has lower enegy demand. That the hybrid air ventilation system has developed by 
older air ventilation conception. And using the monitoring control for carrying out the system in the case of addition fresh air. The hybrid air ventilation system has applied and considered in the part of fresh air temperature and humidity control that referred by DOAS (Dedicated outdoor air system) [3]-[5]. In the case of thermal comfort and indoor air quality are studied by DOAS concept. A most of topic considered attention energy management by using auto system combination with simulation models [6]. In case of some topics was studied the development of thermal comfort models for various climate zone of north-east India. For considratoin is shown 4 condition inddor-outdoor air temperature and relative humidity. The model developed using the measurement data of January and July months and validated with measured data of April and October months. This research proposed that it is not possible to obtain a generalized thermal comfort model for all climate zone due to adaption process, expectation and perception of people are region specific requirement [7].

Heating, Ventilating and air conditioning (HVAC) system in building are designed to provide thermal comfort to maintain indoor air quality (IAQ) Due to HVAC system are often a large percentage of the energy total energy consumption of building. And constitutes $40 \%$ of the primary energy consumed in the US. In this study were performed using the multi zone air flow model CONTAM. Annual energy simulations were also performed in Energy plus. By ventilating at lower rate for $24 \mathrm{~h}$. a day saved energy compared with ventilation at the higher rate prescribed in ASHRAE 62.2 and that the simulated indoor containment concentration did not exceed common benchmark or health guideline [8].

Moreover, the hybrid air ventilation system chooses thermoelectric devices to control temperature. The thermoelectric devices have a performance for thermal and power generation depending on working. For the heating/cooling producing has carried out by an electric current from the power source [9]-[11]. Including applied and combined with other systems [12]-[14]. Therefore, this paper considers the optimization of the hybrid air ventilation is compossed of the thermoelectric devices and silica gels for increasing fresh air by using the monitoring control sensor.

\section{DESCRIPTION SYSTEM}

The experimental prepared for measurement of temperature, humidity and air pollution $\left(\mathrm{CO}_{2}\right)$ condition by using monitoring control system. However the experimental aim of improvement of older air ventilation that using an automatic system in combination with silica gel and thermoelectric

\subsection{Experimental design}

The hybrid air ventilation system had designed similarly with the dedicated outdoor air system. But the hybrid air ventilation system decided smaller than a requirement for replacement older generally air ventilation. This system decided the dimension width, height, and length $30 \mathrm{~cm}$ x $30 \mathrm{~cm} \times 55 \mathrm{~cm}$ respectively. That shown Figure 1. The system consists of a silica gel unit approximately at $5 \mathrm{~cm}$. That contained inside the system. Next, the thermoelectric cooling type (TEC-12708) used 6 modules. That thermoelectric connected in series electric circuit 3 modules, after that parallel electric circuit. The system carried on a base of optimization of reduction humidity, the temperature of outdoor air before transfer to indoor. Including of control $\mathrm{CO}_{2}$ for addition fresh air into the room.
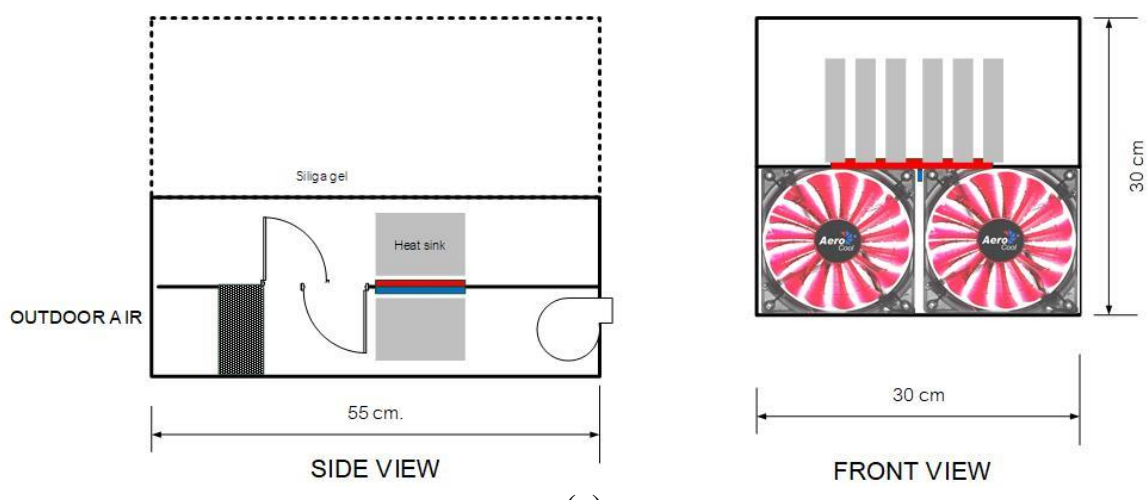

(a) 


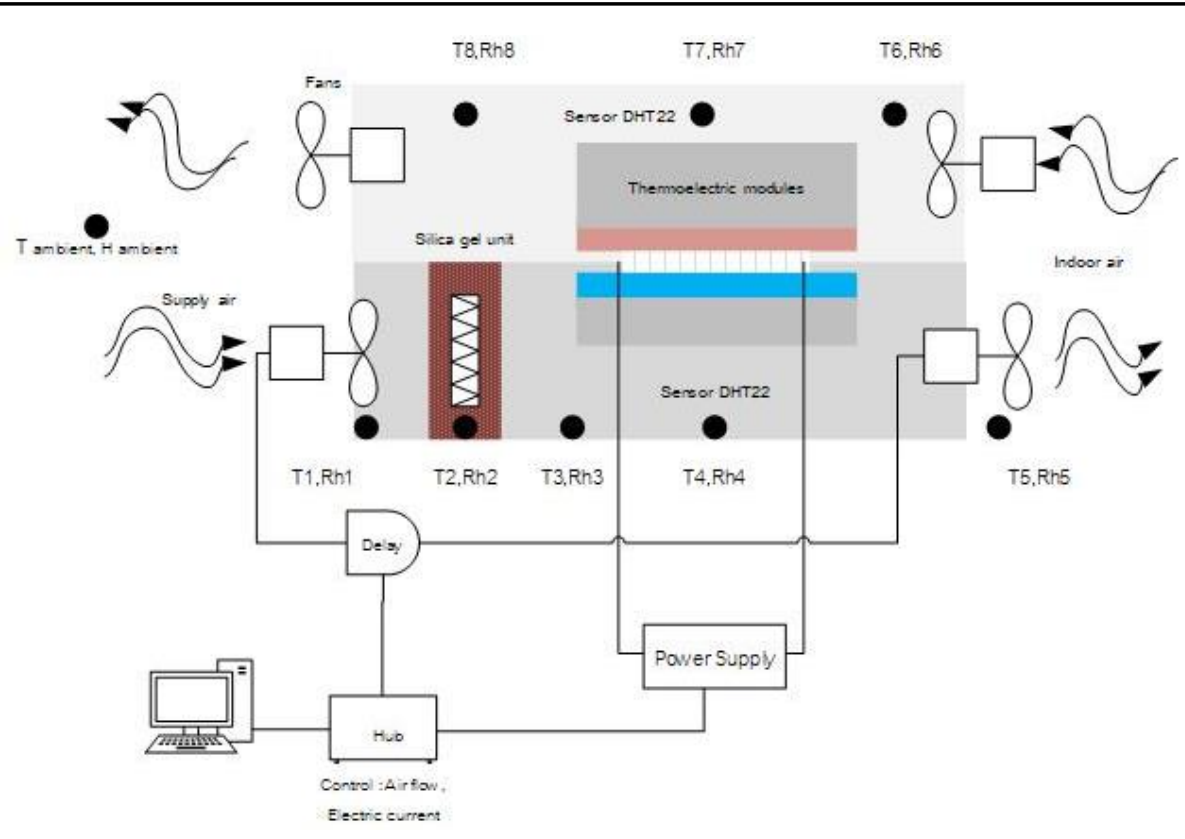

(b)

Figure 1. Design the experimental of hybrid air ventilation (a) Design of hybrid air ventilation system, (b) Sensor and monitoring of hybrid air ventilation system

\subsection{Hybrid air ventilation system process}

The hybrid air ventilation system divide of air chamber into 2 space. The indoor-outdoor air used to flow in the process condition. In the part of consideration divided into 2 pattern: hybrid air ventilation-on or control indoor air quality under ASHRAE 62.2 standard guideline and regeneration dehumidification unit. In this process is brought outdoor air by the fan unit. Next outdoor air is dehumidified by the silica gel unit that running with sensor control. The process decreses the humidity with the silica gel unit before passes to the thermoelectric section. That controls the temperature and humidity of the outdoor air shown as Figure 2 and Figure 3 Meanwhile, the indoor air transferred by the fan unit for increased temperature by the hot side of thermoelectric. Therefore silica gel unit is regenerated by high-temperature form indoor air.

In this experiment carried out between control outdoor air and indoor air quality and regeneration desiccant unit. Although indoor air value unexceed handbook of IAQ standard that was part of improving air quality going to stop. In the same way, the regeneration process will start for recovery desiccant unit that is solid silica gel unit.

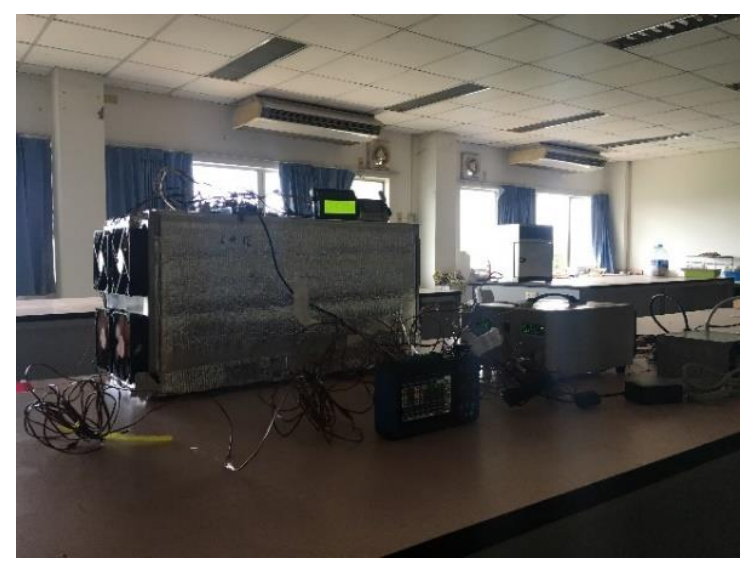

Figure 2. System configuration of hybrid air ventilation system 


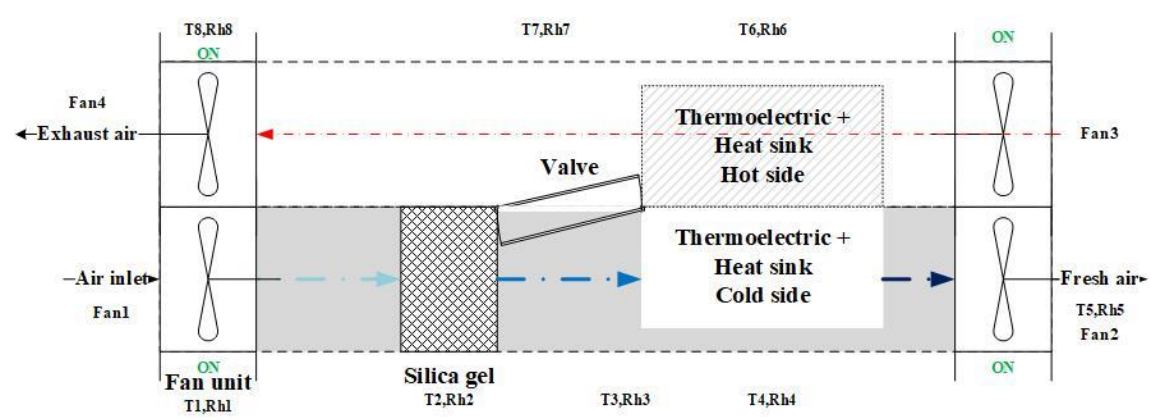

(a)

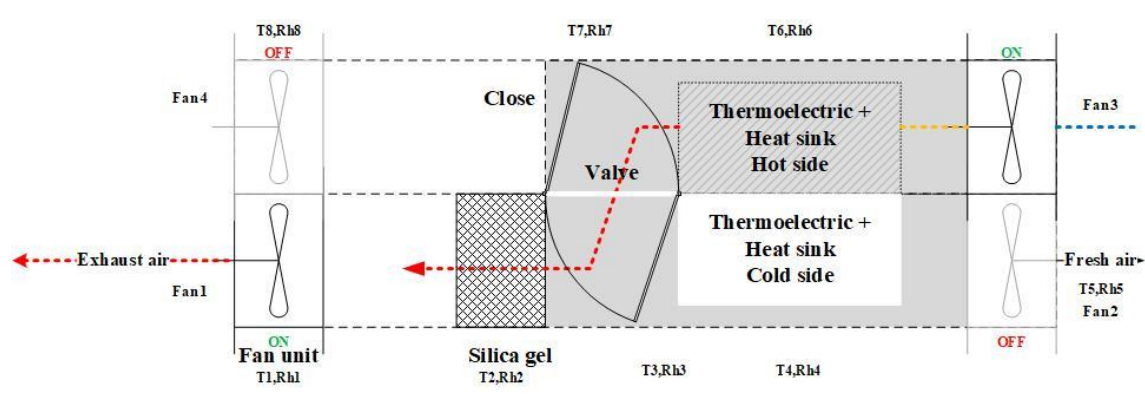

(b)

Figure 3. Performance operated of hybrid air ventilation system: (a) Hybrid air ventilation system-on;

(b) Hybrid air ventilation system-on

Table 1. Specification of thermoelectric in hybrid air ventilation

\begin{tabular}{cccccc}
\hline Material Types & $Q_{\max }(\mathrm{W})$ & $\Delta T_{\max }\left({ }^{\circ} \mathrm{C}\right)$ & $V_{\max }$ & $R \Omega$ & Number of TEC $(n)$ \\
\hline $\begin{array}{c}\text { TEC -Module } \\
12708\end{array}$ & 79 & 75 & 15.4 & 1.5 & 6 \\
\hline
\end{tabular}

\subsection{Thermoelectric and silica gel unit}

The thermoelectric devices used approximately 6 modules in the experimental. That thermoelectric used TEC-12708 cooling types. Table 1 in this research chose 6 modules for producing the temperature difference between the cold side and hot side. Because power supply and specification of thermoelectric had electric potential approximately $12-15 \mathrm{~V}$ could produce $\Delta T=45^{\circ} \mathrm{C}$ if used more than effect to lifetime of thermoelectric. In the same way, the thermoelectric working coupled with silica gel unit. Thus research supposed dehumidification and temperature control shown as Figure 4.

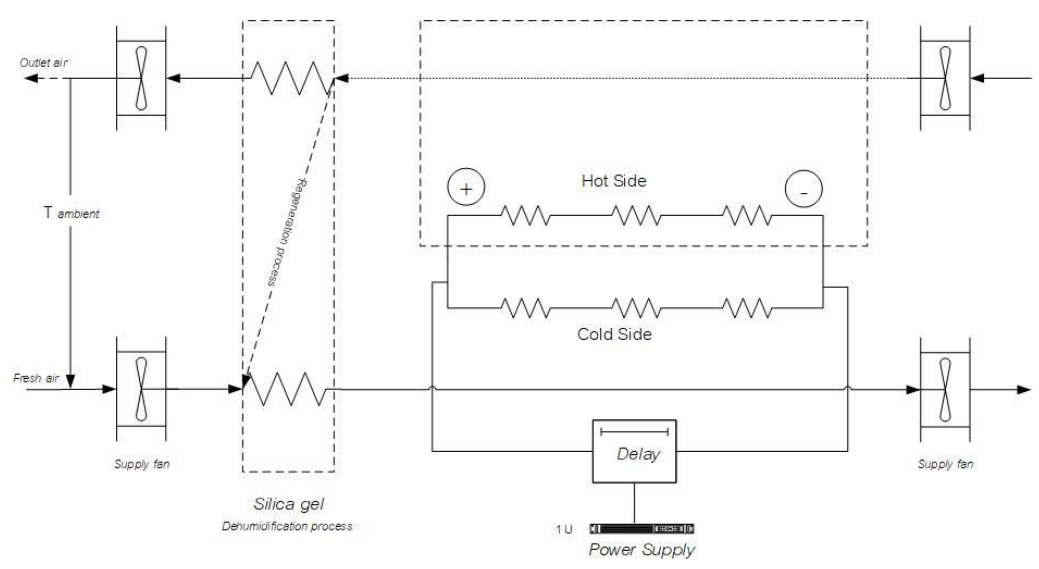

Figure 4. Processing of the hybrid air ventilation system 


\section{MONITORING HYBRID AIR VENTILATION CONTROL}

The hybrid air ventilation working switched depending on a specification of outdoor air flow condition. The processing of the system divided into 2 types. Opening the hybrid air ventilation is controlled by IAQ parameters under ASHRAE 62.2. And the system recovered dehumidification of the silica gel unit. In this process is brought outdoor air by the fan unit. After, the outdoor air is dehumidified by the silica gel unit that running with sensor control. In this process is written by Arduino program for measurement management. The sensor used receiving values for carried out responding with the fan unit and air valves shown as Figure 5. Meanwhile, the indoor air transferred by the fan unit for increased temperature by the hot side of thermoelectric. Therefore silica gel unit is regenerated by high-temperature form indoor air.

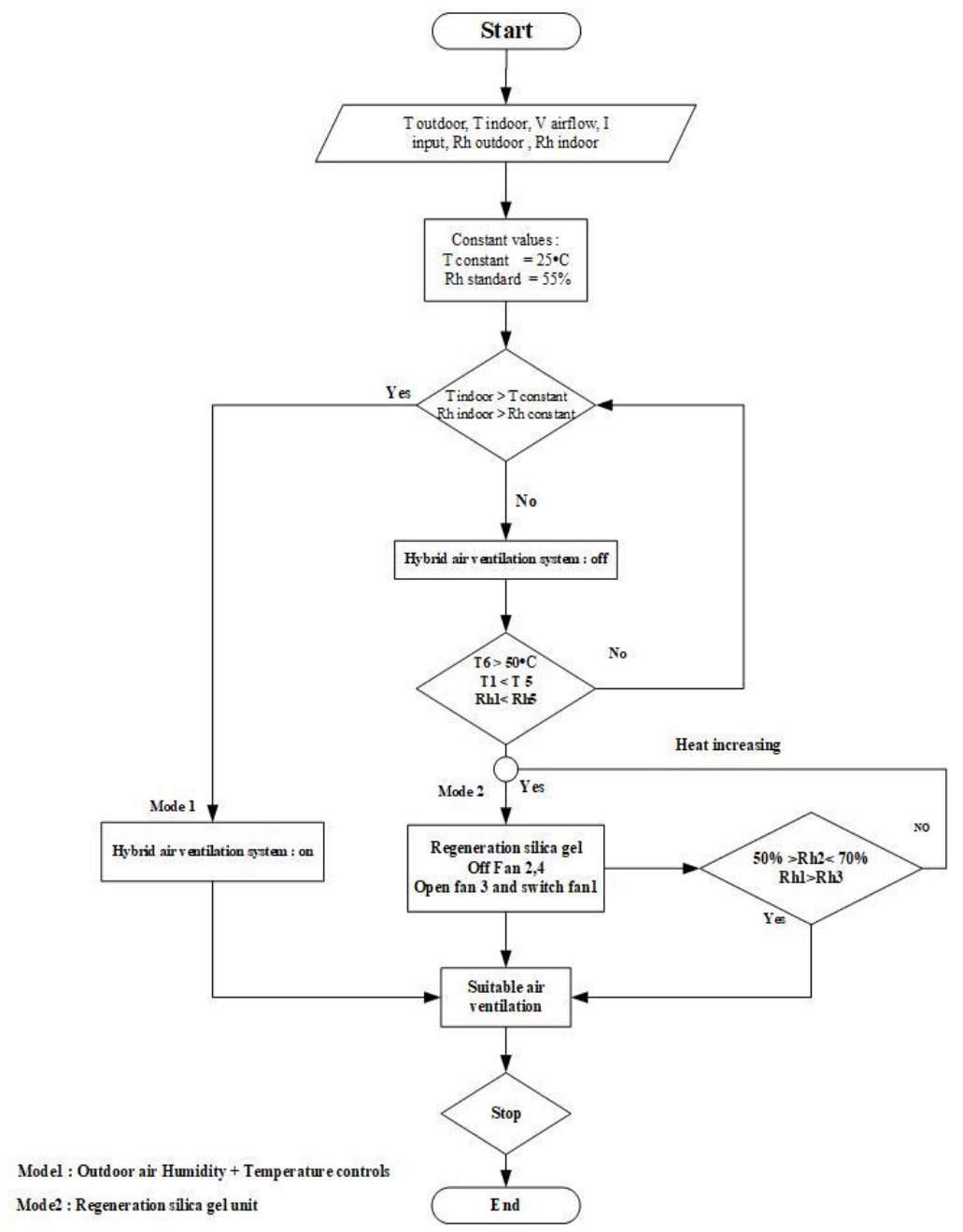

Figure 5. Flowchart of hybrid air ventilation control 


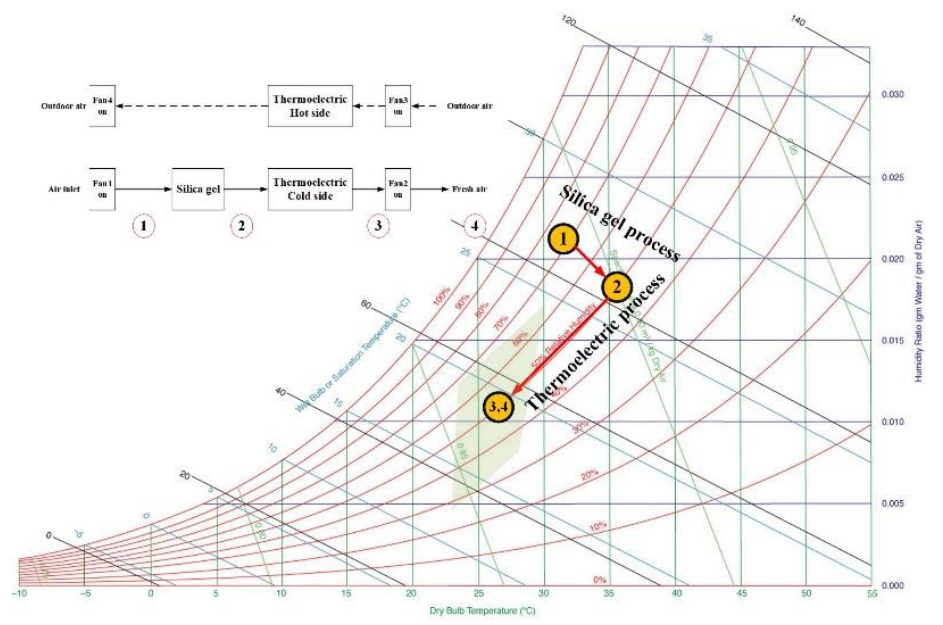

(a)

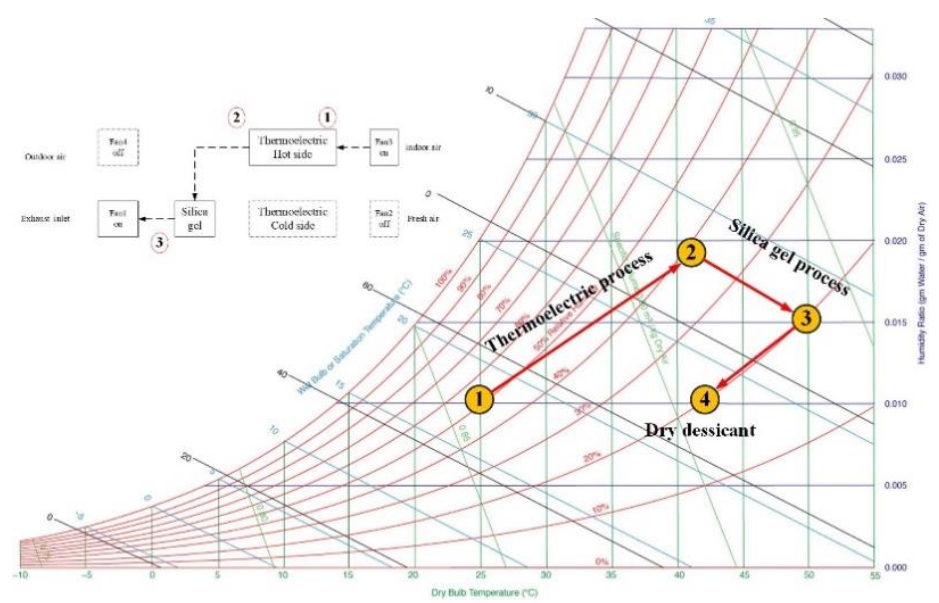

(b)

Figure 6. Psychometric chart of hybrid air ventilation system process: (a) Mode1: Cooling and ventilation on process; (b) Mode2: Regeneration of silica gel

\section{RESULTS AND ANALYSIS}

The indoor temperature and humidity controlled by the hybrid air ventilation including of monitoring sensors for management cases study divided to 4 cases: The electric current of thermoelectric relative indoor air, Thermal comfort and indoor air quality condition, Regeneration of silica gel, $C O P$ of the system.

\subsection{Control temperature and humidity monitoring under electric control}

Figure 7 Show experimental of the hybrid air ventilation at 2 days between 6:00 AM.-12:00 PM in August. This august is a rainy season of Thailand due to during higher humidity. Indoor temperature is proposed thermal comfort zone depended on ASHRAE standard 62.2. The boundary of outdoor temperature during $33-38^{\circ} \mathrm{C}$. Thus in the experimental controlled constant supply air for this operation. The result suggested to an effect of silica gel unit and the thermoelectric module for control temperature and humidity under hot and wet condition. The electrical voltage at $12 \mathrm{~V}$ could be improvement air inlet nearly with thermal comfort standard. Due to the thermoelectric has high temperature that differences effectively to lower of the cold side of thermoelectric, so that air inlet connection with the cooling side had been transferred thermal under thermodynamic principle temperature different of air inlet with fresh air is about $5^{\circ} \mathrm{C}$. In the same way, relative humidity of air inlet is reduced by silica gel unit if compared with outdoor air at average $58.9 \%$ and $62.5 \%$. The dehumidification process proposed by using silica gel unit for absorption humidity of air inlet. But, the silica gel isn't working continuously. Due to silica gel has a saturation point. Therefore, the silica gel unit should be obtained regeneration in during close the hybrid air ventilation system. 


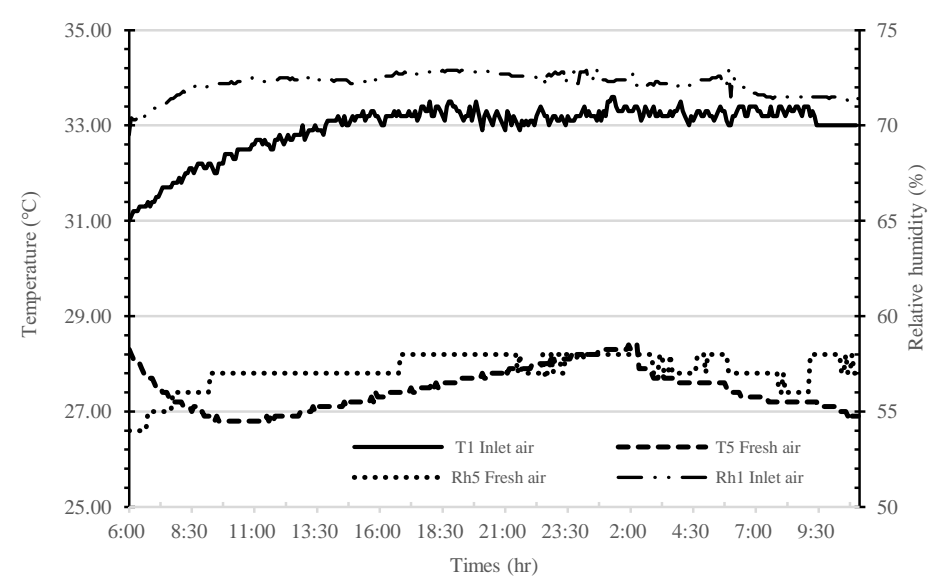

Figure 7. Hybrid air ventilation controlled temperature and humidity at $9 \mathrm{~V}$

\subsection{Control temperature and humidity monitoring under electric control}

The performance methodology called coefficient of performance $(C O P)$ that explained in quantify of process. So, the evaluation of $C O P$ important to consider. Therefore, this paper evaluates of energy consumption of thermoelectric relative to increasing fresh air. The experimental is explained by the equation, which application defined [15],[16].

$$
Q_{c}=c_{p} m_{\text {air }}(\Delta t)
$$

If $Q_{c}$ is the air cooling produced by thermoelectric devices under electric current. $c_{p}$ is the specific heat, $m_{\text {air }}$ is the mass flow rate and $\Delta t$ is the different temperature between cold side of thermoelectric with air temperature across.

$$
C O P_{t e c}=\frac{Q_{c}}{Q_{\text {in }}+W_{\text {tec }}}
$$

$Q_{\text {in }}$ is heat transfer form outdoor into hybrid air ventilation in the part of thermoelectric modules. And $W_{t e c}$ is power supply using for produce temperature different. However coefficient of performance is referenced by energy conservative that using in calculation the indoor air quality handbook [17],[18].

$$
\operatorname{COP}_{\text {hybrid }}=\frac{Q_{o u t}}{Q_{\text {in }}+W_{t e c}+W_{f a n}}
$$

In the part of $C O P_{\text {hybrid }}$ is the coefficient of performance of the hybrid air ventilation system. The calculation method considered by principle of original COP. Table 2 shows the determined COP of thermoelectric of hybrid air ventilation system. Thus the experimental proposed electric current $12 \mathrm{~V}$ most COP when compared with the other. But in the part of energy consumption and lifetime of thermoelectric modules is not suitable for a long time. Due to thermoelectric modules is electronic devices when obtained overheating impacted to efficiency system inside. Therefore electric current at $9 \mathrm{~V}$ has appropriate for saving energy input including of producing temperature comfort zone.

\subsection{Regenerate process}

According to the experimental result as shown in Figure 10. The hybrid air ventilation system combined with thermoelectric and silica gel unit is effected evaluation by regeneration silica gel desiccant. In the case study using thermoelectric hot side for increasing hot air temperature in the exhaust chamber. So, this process affected heat transfer between silica gel with hot air for recovery desiccant handbook approximately $55-70^{\circ} \mathrm{C}[19]-[21]$. Therefore, the experiment proposed of regeneration process regeneration relation times. The results removal humidity of silica gel about $12.66 \%$.

$$
\eta=\frac{R h_{b f}-R h_{a f}}{R h_{b f}} \times 100
$$


where, $\eta$ is the efficiency of removal relative humidity of silica gel unit $R h_{b f}$ and $R h_{a f}$ express for a relative humidity of before and after processing that is equation explained to efficiency calculation method.

Table 2. Experimental condition and consider

\begin{tabular}{lcc}
\hline \multicolumn{1}{c}{ Description } & Hybrid air ventilation system \\
& Mode 1 & $\begin{array}{c}\text { Mode } 2 \\
\text { On }\end{array}$ \\
& \multicolumn{2}{c}{$3,6,9,12 \mathrm{~V}$} \\
Electrical current to Thermoelectric & $\dot{m} / \mathrm{s}$ \\
Fan & \multicolumn{2}{c}{$30 \mathrm{~cm} \mathrm{x} \mathrm{30} \mathrm{cm} \mathrm{x} 5 \mathrm{~cm}$} \\
Silica gel unit & TEC-12708 / 6 modules \\
Thermoelectric modules & Phitsanulok, Thailand \\
Weather location & July - October \\
Experimental period & \multicolumn{2}{c}{} \\
\hline
\end{tabular}

Table 3. Result temperature relative with input voltage of hybrid air ventilation system

\begin{tabular}{cccc}
\hline Input voltage & T1 Inlet air & $\begin{array}{c}\text { Temperature }\left({ }^{\circ} \mathrm{C}\right) \\
\text { T5 Fresh air }\end{array}$ & T8 outdoor air \\
\hline 3 & 33.01 & 31.00 & 32.71 \\
6 & 32.92 & 29.53 & 32.23 \\
9 & 31.48 & 28.40 & 31.57 \\
12 & 31.13 & 28.01 & 31.52 \\
\hline
\end{tabular}

Table 4. Result relative humidity with input voltage of hybrid air ventilation system

\begin{tabular}{cccc}
\hline \multirow{2}{*}{ Input voltage } & Rh1 Inlet air & $\begin{array}{c}\text { Relative humidity (\%) } \\
\text { Rh5 Fresh air }\end{array}$ & Rh8 outdoor air \\
\hline 3 & 70.99 & 62.26 & 65.35 \\
6 & 70.70 & 61.24 & 65.18 \\
9 & 70.71 & 57.62 & 59.15 \\
12 & 70.25 & 56.47 & 59.91 \\
\hline
\end{tabular}

\subsection{Thermal comfort evaluation}

The indoor air has necessary for the human that spent times in the building, while the ventilation system increases thermal comfort zone. The experiment designed by the parameters such as the temperature, humidity and air pollution $\left(\mathrm{CO}_{2}\right)$. The experiment measured spending times of 3-12 hour. That working times under free air flow ventilation rate. So, the hybrid air ventilation system is controlled average temperature and humidity respectively. The experimental is using the electric voltage of $12 \mathrm{~V}$. Therefore could supply fresh air at $28^{\circ} \mathrm{C}$ temperature $58 \%$ relative humidity. However, the outdoor air pollution reduced by hybrid air ventilation system lower than $1,000 \mathrm{ppm}$. That has approximately $600-700 \mathrm{ppm}$ for filter outlet air into indoor. Consider of percentage. Similarly, indoor air pollution reduced $15 \%$ compared with $900 \mathrm{ppm}$ standard to $680 \mathrm{ppm}$ that is condition of $9 \mathrm{~V}$. for carry out of thermoelectric combination with silica gel.

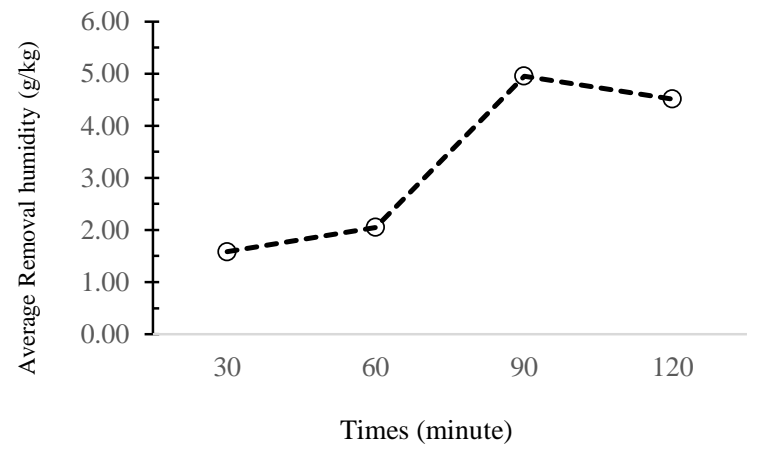

Figure 8. Regeneration relative with time of hybrid air ventilation in the experimental condition 


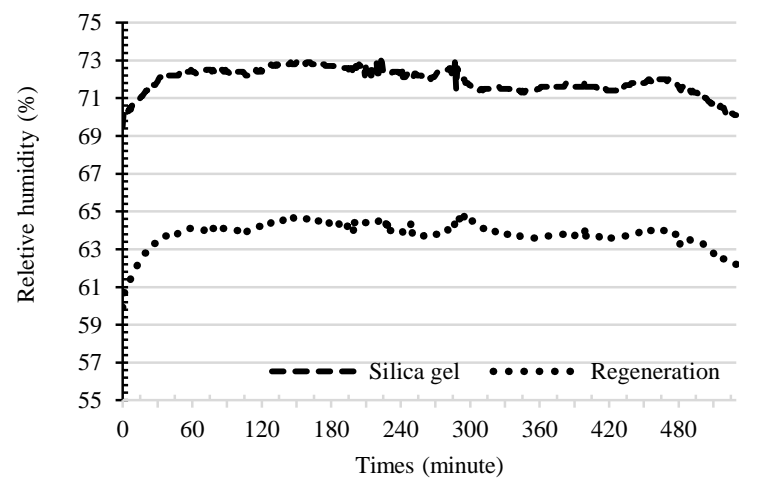

Figure 9. Regeneration relative with time of hybrid air ventilation in the experimental condition

\section{CONCLUSION}

In this research, the optimization of the hybrid air ventilation system combined with silica gel and thermoelectric studied by experimental method. Thus, the main experimental is the optimization of temperature and humidity control including of increasing fresh air as well introducing improve removal air pollution system such as $\mathrm{CO}_{2}$ and use monitoring control for convenience.

The $12 \mathrm{v}$. of thermoelectric could be control temperature and humidity including air pollution $\mathrm{CO}_{2}$ not exceed indoor air quality standard. The power of thermoelctric obtained by power supply. So, should be alternative power source for saving energy consumption. Increasing the system potential of supply fan with bigger than size for addiction a many air inlet for produced fresh air including of setting in the various room. Hybrid air ventilation system is feasible in this study location. So COP of system depends on humidity and temperature of different condition.

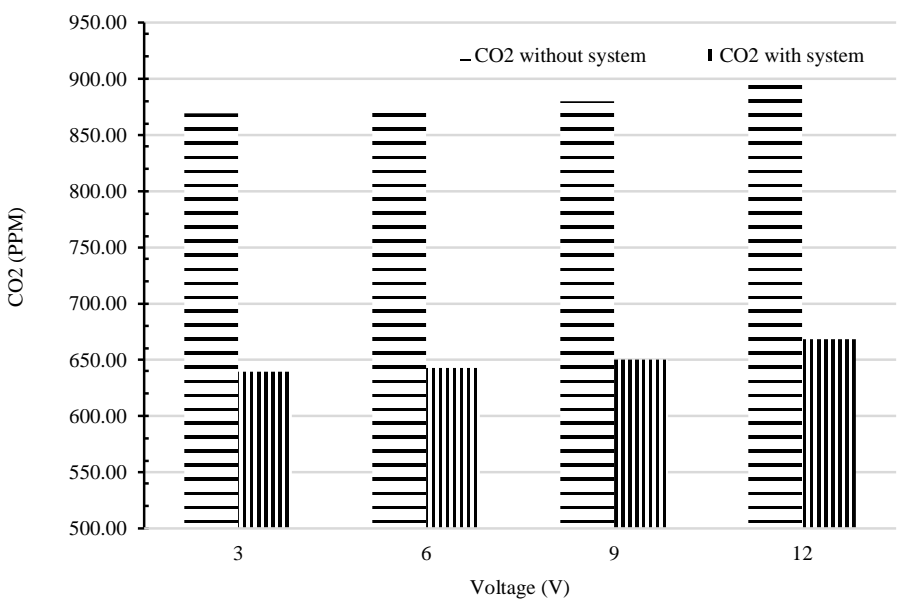

Figure 10. Comparison of performance hybrid air ventilation system reduced carbon dioxide

\section{ACKNOWLEDGEMENTS}

This work was financially supported by the Science Achievement Scholarship of Thailand, Department of physics, Faculty of Science, The Graduate School Naresuan University.

\section{REFERENCES}

[1] Building Green, "We spend 90\% of our time indoor," 2018. https://www.buildinggreen.com/blog/.

[2] EPA, "Indoor Air Fact, Sick Building Syndrome, Air and radiation, Research and Develop," 1991.

[3] ASHREA, "ANSI/ASHREA standard 62.1-2013: Ventilation for Acceptable Air Quality," ASHREA. 
[4] S. A. Mumma and Emeritus, "Understanding and Designing DOAS," http://www.caee.utexas.edu/prof/Novoselac/classes/ARE389H/Handouts/doas_arkansas_final.pdf

[5] Q. J. Kwong, et al., "Thermal comfort assessment and potential for energy efficiency enhancement in modern tropical building: review," Energy and Building, vol. 68, pp. 547-557, 2014.

[6] J. M. Seo, et al., "Possibility of coupling outdoor air cooling and radiant floor cooling under hot and humid climate conditions," Energy and Building, vol. 81, pp. 219-226, 2014.

[7] M. K. Singh, et al., "Development of thermal comfort models for various climate zones of North-East India," Sustainable Cities and Society, vol. 14, pp. 133-145, 2015.

[8] L. C. Ng, et al., "IAQ and energy impact of ventilation strategies and building envelope airtightness in a big box retail building," Building and Environment, vol. 92, pp. 627-634, 2015.

[9] J. G. Via0n, et al., "Numerical modelling and design of a thermoelectric dehumidifier," Applied Energy, vol. 22, pp. 407-422, 2002.

[10] M. J. M. Pathak, et al., "Optimizing limited solar roof access by exergy analysis of solar thermal, photovoltaic, and hybrid photovoltaic thermal system," Applied Energy, vol. 120, pp. 155-124, 2014.

[11] A. A. Angeline, et al., "Performance Analysis of (Bi2Te3-PbTe) Hybrid Thermoelectric Generator," International Journal of Power Electronics and Drive System (IJPEDS), vol/issue: 8(2), pp. 9917-925, 2017.

[12] S. Manjang and S. H. Ahsan, "The Calibration Test of Hybrid Landfill Gas -Photovoltaic-Genset Model in Bontang, East Borneo," International Journal of Power Electronics and Drive System (IJPEDS), vol/issue: 9(1), pp. 89-87, 2018.

[13] A. Jamaluddin, et al., "A Monitoring System of Battery LiFePO4 for Assessment Stand-Alone Street Light Photovoltaic System Based onLabVIEW Interface for Arduino (LIFA)," International Journal of Power Electronics and Drive System (IJPEDS), vol/issue: 8(2), pp. 926-934, 2018.

[14] C. M. Lai, et al., "Optimal spacing for double-skin roofs," Building and Environment, vol. 43, pp. 1749-1754, 2007.

[15] D. S. Song, et al., "Performance evaluation of radiant floor cooling system integrated with dehumidified ventilation," Applied Thermal Engineering, vol. 8, pp. 1299-1311, 2008.

[16] H. M. Kunzel, et al., "Predicting indoor temperature and humidity condition including hygrothermal interaction with the building envelope," Proceeding of International conference on sustainable energy.

[17] W. J. N. Tuner and H. B. Awbi, "Experimental investigation into the thermal performance of residential hybrid ventilation system," Applied Thermal Engineering, vol. 77, pp. 142-152, 2014.

[18] "A practical guide to indoor air quality investigation," Indoor air quality handbook, TSI Incorporated, 2013.

[19] F. Xiao, et al., "Control performance of a dedicated outdoor air system adopting liquid desiccant dehumidification," Applied Energy, vol. 88, pp. 143-149, 2011.

[20] N. Ozislk M., "Heat Transfer a basic approach,” New York, McGall-Hill book co-Singapore, 1985.

[21] Halman J. P., "Heat Transfer," New York, McGall- Hill book co-Singapore. 